\title{
Role of Reducing Agent in Nano Particle Synthesis
}

\author{
Dr. P Vijaya Lakshmi ${ }^{1}$, Dr.Alla Srivani², O Sreedevi ${ }^{3}$ \\ ${ }^{1}$ Assistant Professor, Department of BS\&H, Seshsadri Rao Gudlavalleru Engineering college, \\ Gudlavalleru, Andhra Pradesh \\ ${ }^{2}$ Associate Professor, Department of Science, Vasireddy Venkatadri Institute of Technology, Guntur, Andhra Pradesh \\ ${ }^{3}$ Assistant Professor, Department of BS\&H, Women's Engineering college, Bapatla, Andhra Pradesh
}

\begin{abstract}
Utilization of diminishing specialist is fundamental when you need to make any nano-molecule at its natural state. For eg., the instance of metal nanoparticle, for example, Au, Ag and so forth You might realize that when matter is estimated down, there is a colossal raise in its without surface energy.

This prompts an immense expansion in both synthetic and actual association of the nano particle with its encompassing. In one hand it builds the surface synthetic reactivity. The diminishing specialist lessens the shot at it responding with encompassing particularly to get oxidized.

Then again, the raise in surface free energy likewise actuates its actual reactivity. For instance, prompting molecule conglomeration prompting an increment in the molecule size. Here a size balancing out specialist otherwise called covering specialist will deal with this. In this way, a diminishing specialist plays an alternate part contrasted with that of a covering specialist. Both can be utilized simultaneously. Anyway their singular organization contrast from one case to another contingent upon need. Individuals likewise distinguished a few specialists that can do the double job effectively eg., certain sodium citrate and barely any amines. In any case, this is likewise restricted to the prerequisite/utilization of the nano particle. Since the surface change would impact its exhibition in a given application.
\end{abstract}

Keywords: Reducing agent, Advanced Materials, Nano Materials.

\section{INTRODUCTION:}

Diminishing specialists of silver particles are frequently utilized in the readiness of silver functionalized antimicrobial completions on materials. A methodology for the in situ functionalization of cotton with silver items was depicted . The strategy of screen printing was utilized in this cycle. It includes the screen printing of cotton with a printing glue containing silver particles. UV illumination of the surface completed cotton tests was performed to foster usefulness on the outer layer of the material example.

The creators have reasoned that the completed examples had superb antimicrobial movement. In addition, the antimicrobial action of the examples was held even after various washings, and such a methodology could be easily utilized with other textiles.Several lessening specialists, including sodium borohydride, sodium citrate, and so forth, assume a significant part as diminishing specialists in the development of metal salts into metal nanoparticles. The greater part of the compound responses require a raised temperature however a few responses will decrease to nanoparticles at room temperature.

The warm and Tollens decrease technique was quite possibly the main substance decrease strategy. It acts with the assistance of a few decreasing specialists, like hydrazine or dextrose, for creation of silver nano particles. These diminishing specialists were one of the significant boundary determinations in the shape and size of nano particles for instance. The sunflower-molded AgNPs can be ready by utilizing ascorbic corrosive as a decreasing specialist. Quantity of Reducing Agent is measured. 
International Advanced Research Journal in Science, Engineering and Technology

Impact Factor $7.105 \div$ Vol. 9, Issue 1, January 2022

DOI: 10.17148/IARJSET.2022.9143

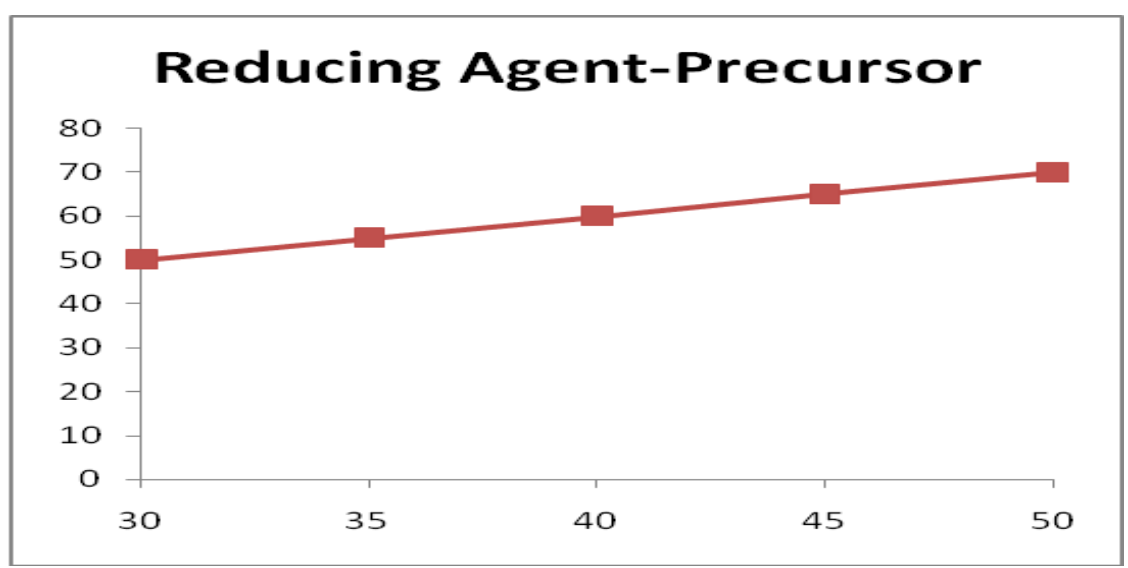

RESULTS:

\begin{tabular}{|c|c|c|c|}
\hline Sl.No & $\begin{array}{l}\text { Reducing Agent } \\
\text { M.W }\end{array}$ & $\begin{array}{l}\text { Precursor } \\
\text { M.W }\end{array}$ & $\begin{array}{l}\text { Quantity of Reducing } \\
\text { Agent } \\
\text { gm }\end{array}$ \\
\hline 1 & 30 & 50 & 3 \\
\hline 2 & 35 & 55 & 4.77 \\
\hline 3 & 40 & 60 & 6.66 \\
\hline 4 & 45 & 65 & 6.92 \\
\hline 5 & 50 & 70 & 7.14 \\
\hline
\end{tabular}

\begin{tabular}{|l|l|l|l|}
\hline Sl.No & $\begin{array}{l}\text { Reducing Agent } \\
\text { M.W }\end{array}$ & $\begin{array}{l}\text { Precursor } \\
\text { M.W }\end{array}$ & $\begin{array}{l}\text { Quantity of Reducing Agent } \\
\text { gm }\end{array}$ \\
\hline 1 & 55 & 75 & 7.33 \\
2 & 60 & 80 & 7.55 \\
3 & 65 & 85 & 7.64 \\
4 & 70 & 90 & 7.77 \\
5 & 75 & 95 & 7.89 \\
\hline
\end{tabular}

\begin{tabular}{|l|l|l|l|}
\hline Sl.No & $\begin{array}{l}\text { Reducing } \\
\text { Agent M.W }\end{array}$ & $\begin{array}{l}\text { Precursor } \\
\text { M.W }\end{array}$ & $\begin{array}{l}\text { Quantity of Reducing Agent } \\
\text { gm }\end{array}$ \\
\hline 1 & 80 & 100 & 8.00 \\
2 & 85 & 105 & 8.09 \\
3 & 90 & 110 & 8.18 \\
4 & 95 & 115 & 8.26 \\
5 & 100 & 120 & 8.33 \\
\hline
\end{tabular}


International Advanced Research Journal in Science, Engineering and Technology Impact Factor 7.105 Vol. 9, Issue 1, January 2022 DOI: 10.17148/IARJSET.2022.9143

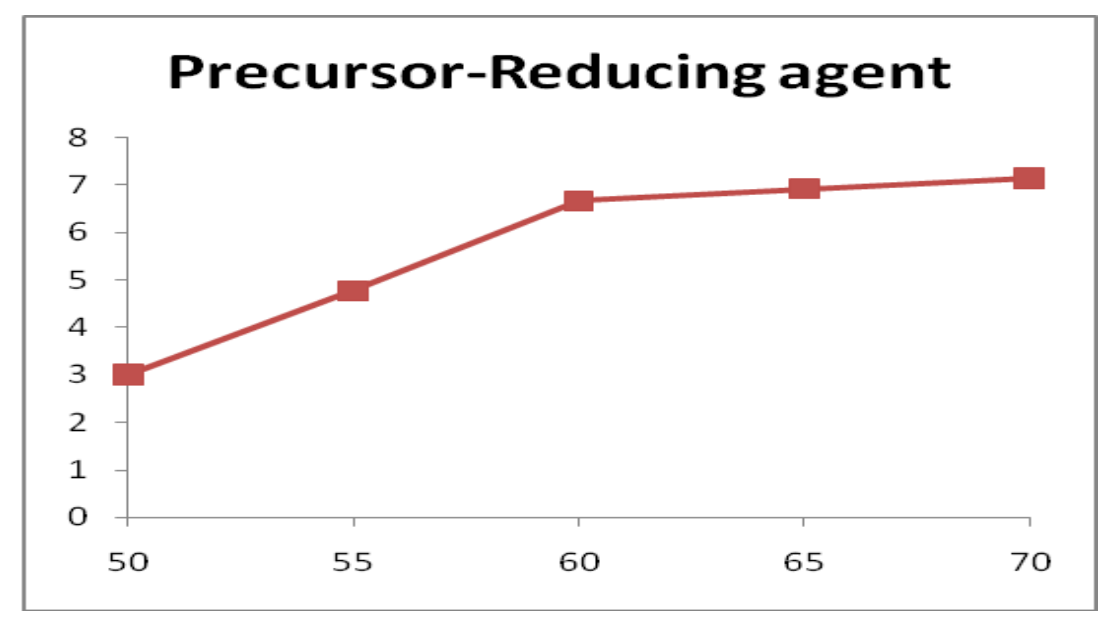




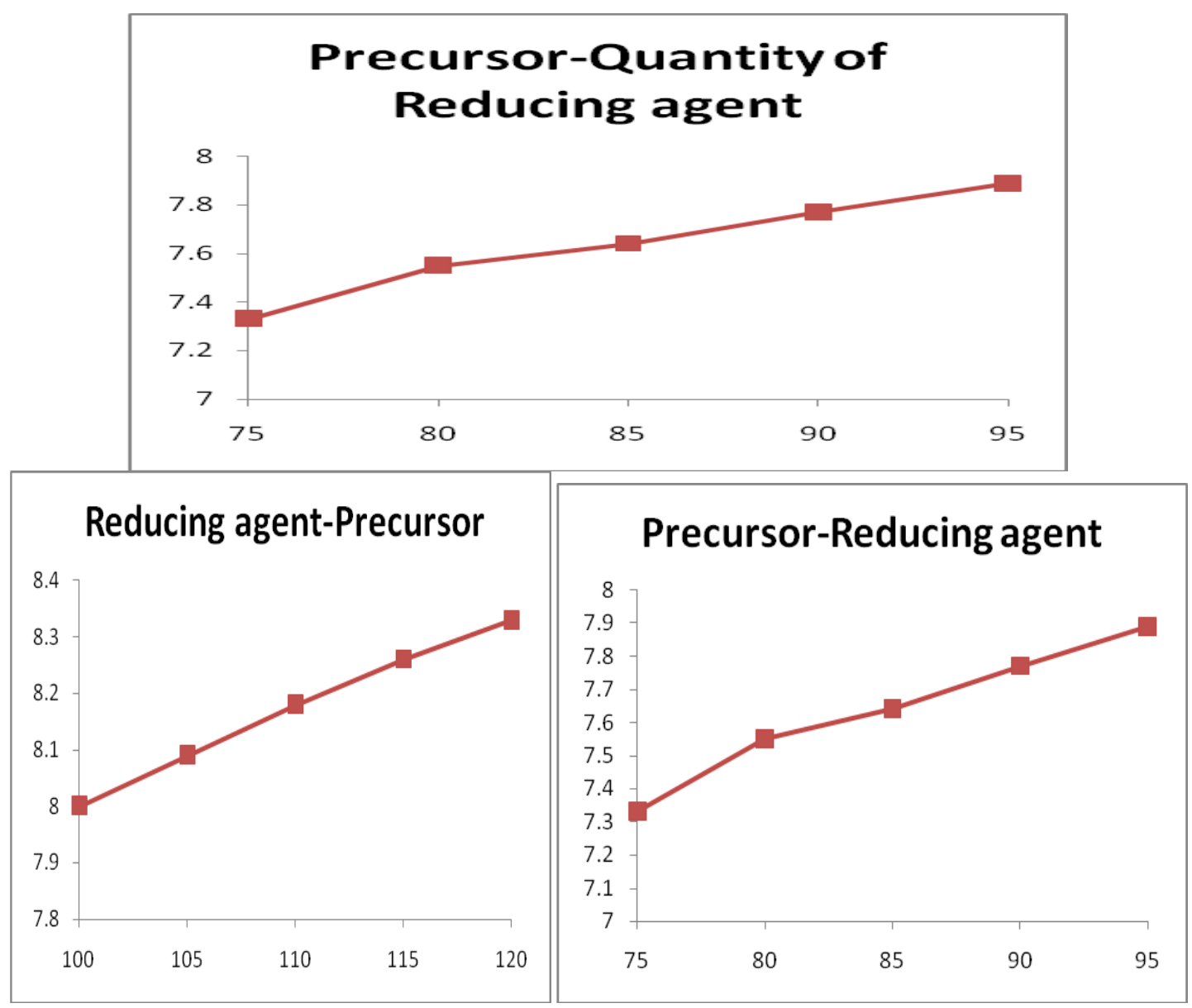

CONCLUSION:

Diminishing specialist is for the most part in one of its lower oxidation states and is known as the electron benefactor. Lessening specialists are normally utilized in protein arrangements to divide the disulfide connection between cysteine amino acids, yet most are utilized in an assortment of different applications across many fields of science.Several diminishing specialists, including sodium borohydride, sodium citrate, and so on, assume a significant part as decreasing specialists in the development of metal salts into metal nanoparticles. The vast majority of the synthetic responses require a raised temperature yet a few responses will decrease to nanoparticles at room temperature. The warm and Tollens decrease technique was perhaps the main synthetic decrease strategy. It acts with the assistance of a few diminishing specialists, like hydrazine or dextrose, for creation of silver nanoparticles. These decreasing specialists were one of the significant boundary choices in the shape and size of nanoparticles for instance. The sunflower-molded AgNPs can be ready by utilizing ascorbic corrosive as a decreasing specialist.

\section{REFERENCES:}

1. Buick, Roger (August 27, 2008). "When did oxygenic photosynthesis evolve?". Philosophical Transactions of the $\begin{array}{llll}\text { Royal Society } & \text { B. } 363 \text { (1504): } & \text { 2731-2743. doi:10.1098/rstb.2008.0041. ISSN 0962- }\end{array}$ 8436. PMC 2606769. PMID 18468984.

2. Sosa Torres, Martha E.; Saucedo-Vázquez, Juan P.; Kroneck, Peter M.H. (2015). "Chapter 1, Section 2: The rise of dioxygen in the atmosphere". In Kroneck, Peter M.H.; Sosa Torres, Martha E. (eds.). Sustaining Life on Planet Earth: Metalloenzymes Mastering Dioxygen and Other Chewy Gases. Metal Ions in Life Sciences volume 15.15. Springer. pp. 1-12. doi:10.1007/978-3-319-12415-5_1. ISBN 978-3-319-12414-8. PMID 25707464.

3. Jump up to: ${ }^{\mathbf{b}}$ "Electrode Reduction and Oxidation Potential Values". www.EESemi.com. Retrieved 12 July 2021.

4. "Standard Electrode Potentials". hyperphysics.phy-astr.gsu.edu. Retrieved 29 March 2018.

5. Aufray M, Menuel S, Fort Y, Eschbach J, Rouxel D, Vincent B (2009). "New Synthesis of Nanosized Niobium Oxides and Lithium Niobate Particles and Their Characterization by XPS Analysis" (PDF). Journal of Nanoscience and Nanotechnology. 9 (8): 4780-4789. doi:10.1166/jnn.2009.1087. PMID 19928149.

6. http://bbc.co.uk/bitesize/guides/zx2bh39/revision/5 